\title{
Measuring chordae tension during transapical neochordae implantation: Toward understanding objective consequences of mitral valve repair
}

\author{
Daniel Grinberg, MD, ${ }^{\mathrm{a}, \mathrm{b}, \mathrm{c}}$ Pierre-Jean Cottinet, $\mathrm{PhD},{ }^{\mathrm{b}}$ Sophie Thivolet, MD, ${ }^{\mathrm{a}}$ David Audigier, $\mathrm{PhD},{ }^{\mathrm{b}}$ \\ Jean-Fabien Capsal, $\mathrm{PhD},{ }^{\mathrm{b}}$ Minh-Quyen Le, $\mathrm{PhD},{ }^{\mathrm{b}}$ and Jean-François Obadia, $\mathrm{MD}, \mathrm{PhD}^{\mathrm{a}}$
}

\begin{abstract}
Objectives: Complex structure of mitral valve and its central position in the heart limit assessment of mitral function to standardized calculated parameters assessed using medical imaging (echocardiography). Novel techniques, which allow mitral valve repair (MVr) in a beating heart, offer the opportunity for innovative objective assessment in physiologic and pathologic conditions. We report, to our knowledge, the first data of real-time chordal tension measurement during a transapical neochordae implantation.
\end{abstract}

Methods: Seven patients with severe degenerative mitral regurgitation due to posterior prolapse underwent transapical MVr using the NeoChord DS 1000 (NeoChord Inc, Minneapolis, Minn). During prolapse correction, the tension applied on the neochordae was measured in addition to hemodynamic and echocardiographic parameters.

Results: The traction applied on 1 chorda sustaining the P2 segment was measured at between 0.7 and $0.9 \mathrm{~N}$, and oscillated with respiration. When several neochordae were set in tension, this initial tension was spread homogeneously on each chorda (mean sum of the amplitude of tension $0.98 \pm 0.08 \mathrm{~N}$ ). To achieve an optimal echocardiographic correction, a complementary synchronous traction on all chordae was required. During this adjustment, the sum of the tension decreased (mean $12 \pm 2 \% ; P=.018$ ), suggesting that when normal physiology was restored, the valvular apparatus was in a low-stress state. This method allowed us to apply a precise and reproducible technique, leading to a good procedural success rate with a low morbidity and mortality rate.

Conclusions: The tension applied on chordae during transapical implantation of neochordae for degenerative mitral regurgitation can be measured, providing original data about the objective consequences of MVr on the mitral apparatus. (J Thorac Cardiovasc Surg 2019;158:746-55)

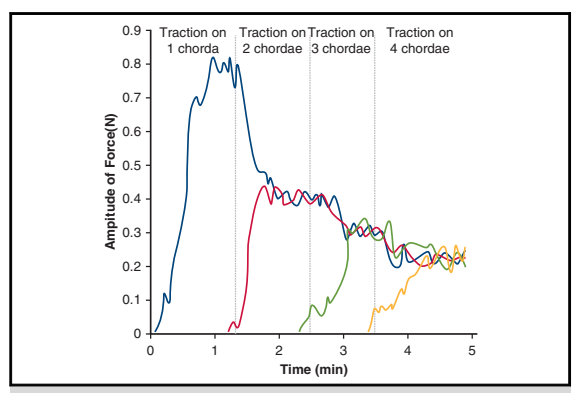

Real-time chordal tension measurement during a transapical neochordae implantation.

\section{Central Message}

Tension applied on chordae sustaining P2 segment was $0.8 \mathrm{~N}$ and was spread homogeneously to all chordae. When normal physiology was restored, the subvalvular apparatus was in a low-stress state.

\section{Perspective}

We experienced a surgical strategy on the basis of objective, quantitative parameters instead of only echocardiogram. New tools are needed to explore hypotheses raised by this work. The prognostic value of the measured tension has to be evaluated. Our protocol is more precise and practical than the current standard for final adjustment of chordae length. The platform could be used even without tension assessment.

See Commentaries on pages 756 and 758 .
From the a Department of Adult Cardiac Surgery, Hôpital cardiologique Louis Pradel, Lyon Medical School, 28, Avenue du Doyen Lépine, 69677 Bron, France; ${ }^{b}$ Univ Lyon, INSA-Lyon, LGEF (Lab of electrical engineering and ferroelectricity), Villeurbanne, France; and ${ }^{\mathrm{c}}$ Department of Cardiovascular Surgery, Mount Sinai Hospital, New York, NY.

The authors received private funding for this research from the Fulbright program, the "Fédération Française de Cardiologie" Doctoral Fellowship program, and the Centre d'Investigation Clinique of Hospice Civils de Lyon.

Received for publication May 10, 2018; revisions received Sept 17, 2018; accepted for publication Oct 2, 2018; available ahead of print Nov 16, 2018.

Address for reprints: Daniel Grinberg, MD, Sinai BioDesign Icahn School of Medicine at Mount Sinai Hospital, 1428 Madison Ave, BMC-24, New York, NY 10029 (E-mail: daniel.grinberg.pro@gmail.com).

$0022-5223 / \$ 36.00$

Copyright $($ c 2018 by The American Association for Thoracic Surgery

https://doi.org/10.1016/j.jtcvs.2018.10.029
Mitral valve repair (MVr) remains the gold standard for treating primary mitral regurgitation (MR). ${ }^{1}$ The technique has since evolved, and today the trend is to use more Gore-Tex sutures to replace the elongated or ruptured chordae and to resect less tissue, thereby creating a larger

Scanning this $\mathrm{QR}$ code will take you to the article title page to access supplementary information. 

Abbreviations and Acronyms
$\mathrm{DMR}=$ degenerative mitral regurgitation
$\mathrm{MR}=$ mitral regurgitation
$\mathrm{MVr}=$ mitral valve repair
$\mathrm{TEE}=$ transesophageal echocardiography

surface of coaptation. ${ }^{2}$ One of the main difficulties of this technique is to define the appropriate length of the chordae assessed on an empty nonbeating heart.

A change of paradigm recently occurred with the introduction of novel techniques performed on beating hearts like transapical neochordae using the NeoChord DS 1000 (NeoChord Inc, Minneapolis, Minn). These devices allow real-time adaptation of the repair thanks to an intraoperative transesophageal echocardiography (TEE) control.

We designed a device that enables a precise traction control on each chorda to determine the optimal length of the chordae during the NeoChord implantation, as well as measuring the tension applied on neochordae along this traction.

We also recorded original results on chordae tension in vivo that have not been previously described to our knowledge, illustrating the physiology and the pathophysiology of the mitral valve.

\section{METHODS \\ Patients}

Because the use of the NeoChord is not yet included in international guidelines, it was only proposed to patients with severe symptomatic MR due to a posterior prolapses, involving mainly the P2 segment (with a variable extension on P1 or P3, but never involving the commissures or the anterior leaflet) and considered as high-risk for conventional surgery (mainly because of frailty) after selection by our heart team.

Informed consent was obtained from each patient about the complete procedure and to acknowledge that their medical records would be collected in a registry. This procedure received the approval of the Ethical Committee of the French Society of Cardiology.

\section{Original Operative Technique}

The usual NeoChord implantation protocol ${ }^{3}$ can be summarized as: access to the left ventricular apex; establishment of 2 apical purse strings for the introduction of the device after systemic heparinization; implantation of several neochordae through the free edge of the prolapsed leaflet using 3-D TEE control; fine adjustment of neochordae length using manual traction on each chordae to achieve the best coaptation under TEE control; fixing the chordae at the apex of the left ventricle at the predefined optimal length; protamine infusion; drainage; and closing. Our conventional institutional anesthesiologic protocol was followed to maintain a mean blood pressure between 70 and $80 \mathrm{~mm} \mathrm{Hg}$.

\section{Modification of the Technique}

Using the original technique, the adjustment of the tension is delicate and approximate because it is performed manually. To improve the safety, the precision, and the reproducibility of this adjustment, we developed and patented a specific adjustment device in collaboration with a team of engineers (LGEF at INSA-Lyon; Figure 1). The device consists of 4 identical units. Each unit consists of a crocodile clip system connected to a force sensor (the force range and the resolution of the load cell are $\pm 10 \mathrm{~N}$ and $0.01 \mathrm{~N}$, respectively) held on a manual linear axis system (micrometric

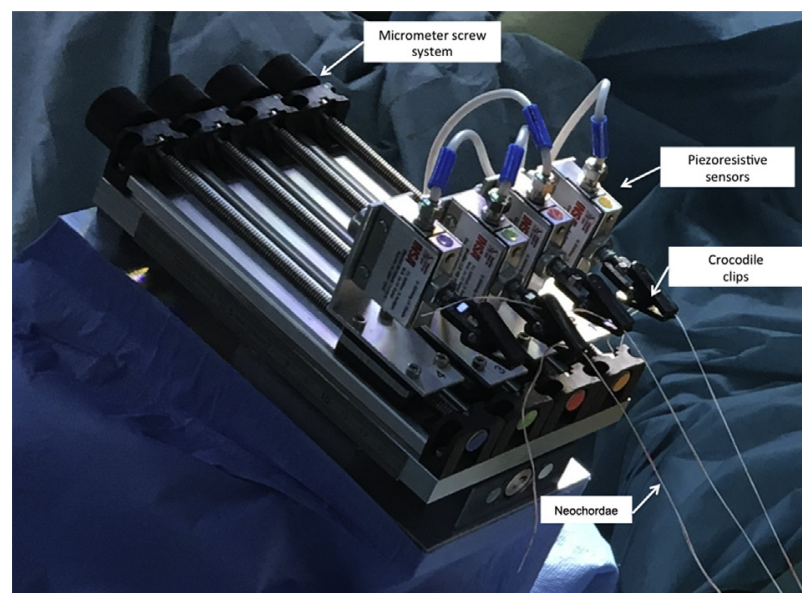

FIGURE 1. The novel chordae tension measuring device allows the assessment of tension applied on neochordae during a transapical implantation. This picture shows the platform after fixation of 3 neochordae. Each neochordae is attached to a piezoresistive sensor thanks to a crocodile clip. The micrometer screw system allows pulling of each chordae one after the other or all simultaneously.

leadscrew). It is, therefore, possible to independently adjust the transverse tension exerted on each chorda connected to the force device. The 4 units are fixed on a 120-mm stroke-length linear table. Such a configuration enables the system to apply the same mechanical traction to all 4 chordae synchronously using the principal screw. The whole device remains lightweight, compact, and easy to transport. Three to 4 NeoChords are usually required to hold the entire free edge of the prolapsed segment, and this statement can by validated by performing a brief manual traction on all chordae using TEE control. After this step the measurement tool is brought closer to the patient. The implanted neochordae are then connected to the force device through the crocodile clips.

The measurement procedure consisted of 4 steps, as follows (Table 1): (1) the chorda implanted in the best location (in the middle of the prolapse) was tracked alone until the best TEE control; (2) the other chordae were then tracked, one at a time, with an individual screw to achieve an equivalent tension on all chordae; (3) all neochordae were then tracked together under TEE control, until obtaining the optimal MVr (no residual MR, vanishing of leaflet billowing, and homogeneous and high coaptation height); and (4) the chordae are then fixed at the apex of the left ventricle at the optimal length. During all steps, we continuously recorded the chordae tension, electrocardiogram, radial blood pressure, 3-D TEE, and surgical view (Figure 2 and Video 1).

\section{Statistical Analysis}

Baseline and demographic categorical variables are expressed as percentages, whereas quantitative variables are expressed as median

TABLE 1. Steps of the measurement protocol

\begin{tabular}{ll}
\hline Step & \multicolumn{1}{c}{ Description } \\
\hline 1 & $\begin{array}{c}\text { Traction of the chorda implanted in the best location until } \\
\text { best correction } \\
\text { Traction of all chordae one after the other until homogeneous } \\
\text { tension }\end{array}$ \\
\hline 3 & $\begin{array}{l}\text { Synchronous traction until optimal TEE correction } \\
4\end{array}$ \\
\hline
\end{tabular}

TEE, Transesophageal echocardiography. 


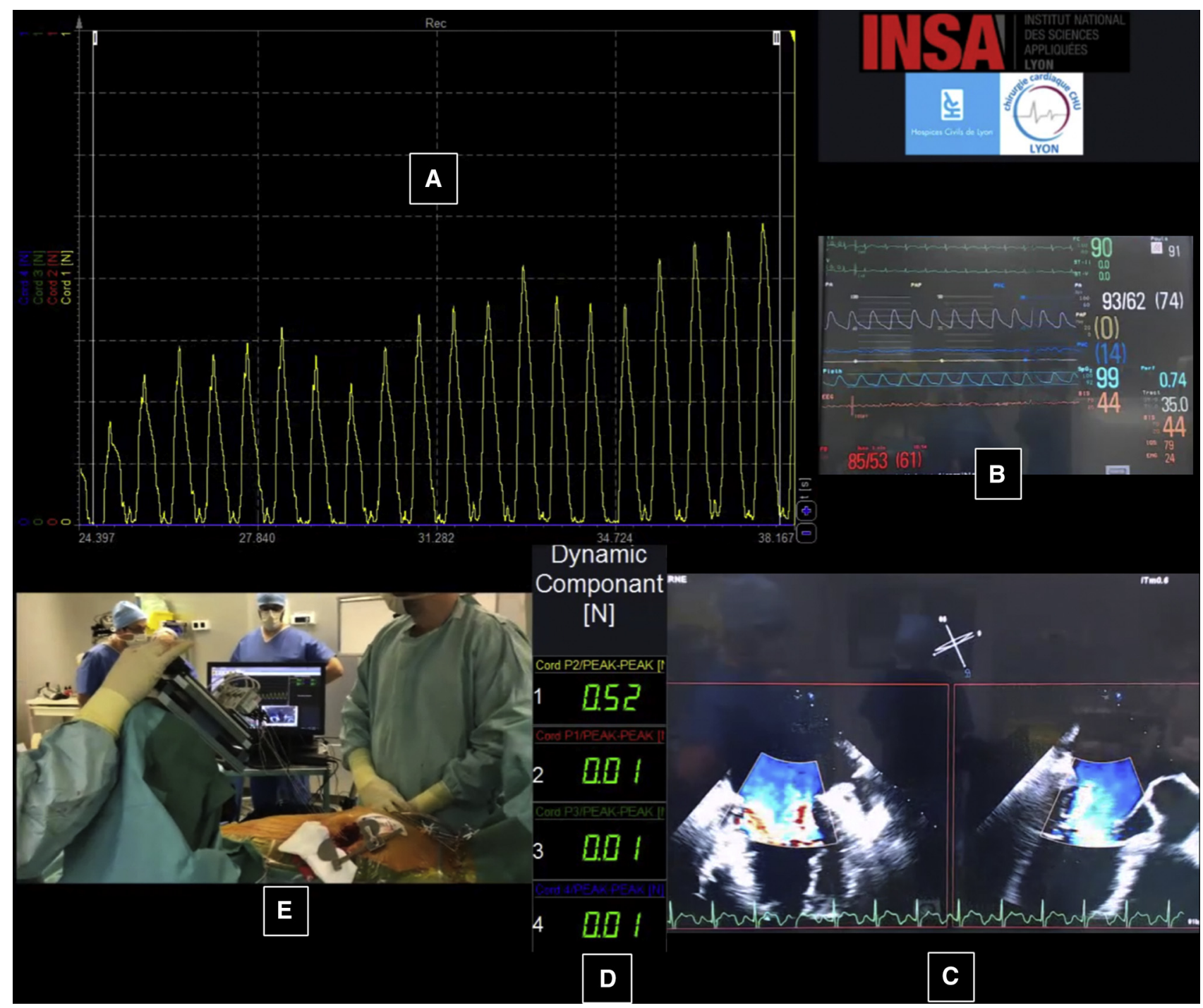

FIGURE 2. The intraoperative screen control shows simultaneously: A, chordae tension curve; B, hemodynamic parameters; C, Transesophageal echocardiography X-plan view; D, chordae tension value for each sensor; and E, operative view. These screenshots were taken during step 1 of the procedure: a single chorda was pulled, and the tension increased progressively (yellow curve, value $0.52 \mathrm{~N}$ ).

(first and third quartiles; interquartile range). Chordae tensions are expressed as mean \pm standard deviation of peak-to-peak amplitude value because they are the physical parameters representing the force that sustained the mitral valve. It is therefore more relevant to know the extrema to not exceed the critical values. In addition, an average measurement is achieved in real time to avoid noise of the sensors and of the electronic conditioning. Categorical variables are presented as numbers with percentages.

The Wilcoxon paired test was used to compare chordal tension before and after optima correction. A $P$ value $<.05$ was considered to be significant. SPSS statistical software was used (SPSS Statistics, version 24.0; IBM Corp, Armonk, NY).

\section{RESULTS}

Clinical Results (Aside From Intraoperative Tension Measurements)

From January 1, 2016, to September 1, 2017, 7 consecutive patients underwent transapical neochordae implantation using the NeoChord DS 1000. The characteristics and operative data of the 7 patients are presented in Table 2 . The adjustment duration appears to have been reduced compared with the standard protocol. The procedural success (defined as residual MR $<2$ ) was obtained in all patients.

The median per-procedural autologous autotransfusion volume (from cell-saver) was $750 \mathrm{~m}$ : (interquartile range, 635-1025), and no patient required postoperative heterologous transfusion. The mean hemoglobin level at discharge was $10.2 \mathrm{~g} / \mathrm{dL}^{-1}$. No perioperative infection and no deaths were observed after a median follow-up of 8 months (interquartile range, 5-11 months).

During initial follow-up, 1 patient had an early recurrence of severe MR due to a tear in a cleft-like indentation adjacent 


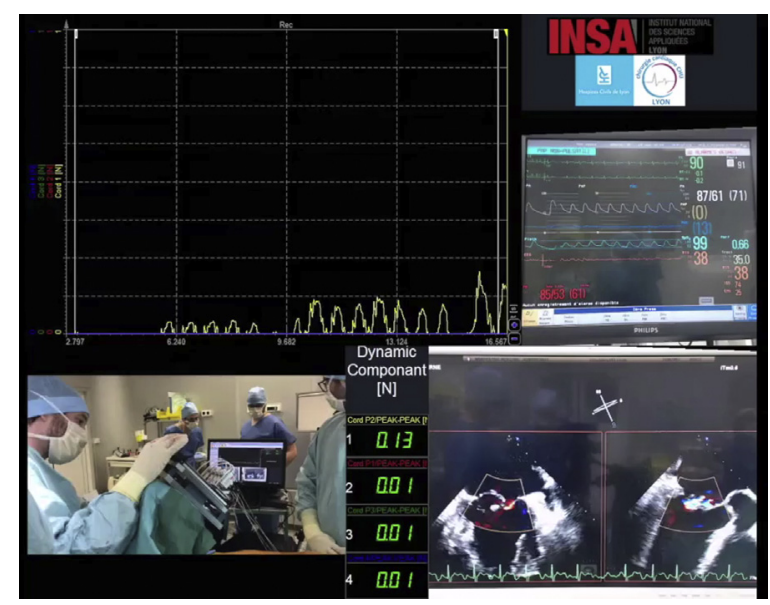

VIDEO 1. Example of chordal tension measurement in 1 patient, after implantation of 4 NeoChords for a posterior prolapse. Video available at: https://www.jtcvs.org/article/S0022-5223(18)32780-6/fulltext.

to the repaired $\mathrm{P} 2$ prolapse. He had a successful minimally invasive MVr 4 months after the NeoChord procedure.

\section{Tension Data During the Length Adjustment Phase} Traction of the chorda implanted in the best location until best correction (step 1). The amplitude of force increased progressively until it reached a plateau value between 0.7 and $0.9 \mathrm{~N}$ (Figure 3). This value was similar for all patients. Interestingly, in all evaluations, we noticed an oscillation in the amplitude of tension of approximately $13 \%$ that followed the respiratory cycles (Figure 3).

Traction of all chordae one after the other until homogeneous tension (step 2). When we were setting the tension of the chordae, one at a time, aiming to achieve the same tension in all chordae, we observed a decrease in tension on chordae previously set in tension. At the end of step 2, the tension initially measured on the first chorda was divided by the number of chordae set in tension. For example, when a tension of $0.8 \mathrm{~N}$ was observed with one chorda, it decreased to 0.2 to $0.3 \mathrm{~N}$ when 4 chordae were set in tension (Figure 4). At the end of step 2 the mean of the sum of the amplitude of tension in all patients was $0.98 \pm 0.08 \mathrm{~N}$.

A final adjustment using TEE control (step 3). At this point of our protocol, some degree of regurgitation usually persisted, thus requiring a final adjustment by synchronous traction on all of the chordae, until optimal TEE results were achieved (no residual MR, vanishing of leaflet billowing, and homogeneous and high coaptation height). Although the initial mean of the sum of the amplitude of tension was $0.98 \pm 0.08 \mathrm{~N}$ before optimal correction of $\mathrm{MR}$, it decreased gradually to $0.87 \pm .07 \mathrm{~N}$ after the correction of regurgitation, corresponding to a $12 \pm 2 \%$ decrease (range, $10.3 \%-14.1 \% ; P=.018$ ) during step 3 (Figure 5).
TABLE 2. Patient characteristics $(N=7)$ and operative data

\begin{tabular}{|c|c|}
\hline Characteristic & Value \\
\hline \multicolumn{2}{|l|}{ Baseline clinical data } \\
\hline Age & $80(63-82)$ \\
\hline NYHA III/IV & $5(71)$ \\
\hline Previous cardiac surgery & $0(0)$ \\
\hline EuroSCORE 2 & $1.4(1.1-2.8)$ \\
\hline \multicolumn{2}{|l|}{ Baseline echocardiographic data } \\
\hline LVEF, \% & $66(57-68)$ \\
\hline SPAP, mm Hg & $50(45-61)$ \\
\hline Severe MR & $7(100)$ \\
\hline EROA, $\mathrm{cm}^{2}$ & $0.51(0.47-0.58)$ \\
\hline Posterior prolapse & $7(100)$ \\
\hline P2 segment & $5(71)$ \\
\hline $\mathrm{P} 1 / \mathrm{P} 2$ segments & $1(14)$ \\
\hline P2/P3 segments & $1(14)$ \\
\hline LA volume $\left(\mathrm{cm}^{2}\right)$ & $33(27-36)$ \\
\hline LVDd, mm & $59.5(55-63)$ \\
\hline \multicolumn{2}{|l|}{ Operative data } \\
\hline Number of neochordae implanted & $3(3-4)$ \\
\hline Posterior localization & $7(100)$ \\
\hline Operative time, minutes & $117(114-126)$ \\
\hline Autotransfusion volume, $\mathrm{mL}$ & $750(635-1025)$ \\
\hline Initial technical success & $7(100)$ \\
\hline Conversion to conventional surgery & $0(0)$ \\
\hline \multicolumn{2}{|l|}{ 30-Day outcomes } \\
\hline ICU stay, d & $1(1-1.5)$ \\
\hline Hospital stay, d & $9(8-13)$ \\
\hline \multicolumn{2}{|l|}{ Discharge TTE } \\
\hline None or mild MR & $6(86)$ \\
\hline Moderate MR & $1(14)$ \\
\hline Severe MR & $0(0)$ \\
\hline Surgical revision for bleeding & $0(0)$ \\
\hline \multicolumn{2}{|l|}{ Relevant adverse event } \\
\hline Stroke & $1(14)$ \\
\hline Perioperative infection & $0(0)$ \\
\hline Transfusion & $0(0)$ \\
\hline Death & $0(0)$ \\
\hline
\end{tabular}

Data are expressed as median (1-3 quartile) or n (\%). NYHA, New York Heart Association; $L V E F$, left ventricular ejection fraction; $S P A P$, systolic pulmonary arterial pressure; $M R$, mitral regurgitation; $E R O A$, effective regurgitant orifice area; $L A$, left atrium; $L V D d$, left ventricle diastolic diameter; $I C U$, intensive care unit; TTE, transthoracic echocardiogram.

\section{DISCUSSION}

\section{What Did We Already Know?}

The study of objective physical consequences of MVr remains limited by the central position of the valve in the heart and its complex structure. To date, our knowledge about chordae tension has previously relied entirely on animal experimental models.

In vitro studies have been published using an ovine experimental model. ${ }^{4-8}$ The valvular tissue is harvested en masse (ring, valve, and mitral subvalvular apparatus). The valve and the papillary muscle are attached to a left 


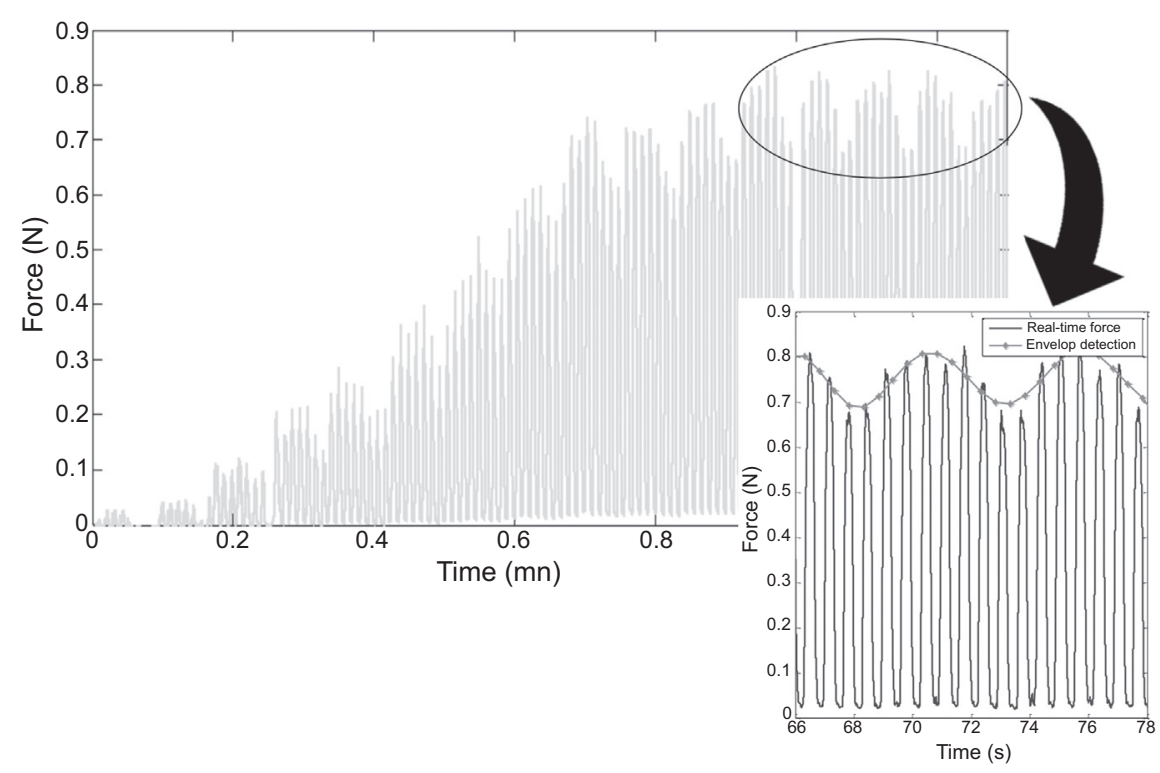

FIGURE 3. The amplitude of tension during step 1 of the protocol: we started pulling the first chordae implanted in the middle of the prolapse zone. During this traction the amplitude of tension increased until it reached a plateau value between $0.7 \mathrm{~N}$ and $0.9 \mathrm{~N}$. The tension oscillated, and the oscillation corresponded to the mechanical ventilation.

ventricular simulator, which can mimic the physiological hemodynamic regimen of the left ventricle. A miniature $\mathrm{C}$-shaped force transducer is sutured in the middle of a chorda. Interesting data were thus obtained, in particular concerning the differences in tension between marginal, struts, and basal chordae. ${ }^{7} \mathrm{He}$ and Jowers proposed an alternative method to reduce interference between the movements of the chordae and the valve. ${ }^{9}$ This consisted of measuring the longitudinal tension of the chordae by an extrapolation of the measurement of the transverse tension of the chordae fibers. A small sensor (elliptical AFP4, Microstrain Inc, Williston, Vt) is inserted within the same chordae. Both approaches remain highly experimental.

Few in vivo studies have been published using a porcine experimental model. ${ }^{10} \mathrm{~A}$ dedicated in-line premounted force transducer is inserted between the papillary muscle and the leaflet, and the strain gauge wire is exteriorized through the apex. This model is the one that most approaches our technique, and the measured tensions are close to the values reported herein.

The transapical neochordae implantations allow direct measurements of the tension applied on the neochordae of a mitral valve in a human beating heart for the first time. These data, formerly inaccessible, are thus innovative.

\section{What Does Our Study Reveal?}

We report data relevant to the function of the mitral subvalvular apparatus in a beating heart. Our tension measurements, recorded throughout the cardiac cycle (from prolapse to tethered chordae), led us to the following conclusions.
The tension applied to chordae holding 1 mitral segment is relatively low $(0.8-1 \mathrm{~N})$. The stress-strain curves of a native chordae had been reported by Zuo and colleagues, showing ultimate stress values around $35 \mathrm{MPa}$ (equal to $35 \mathrm{~N} / \mathrm{mm}^{-2}$ ). ${ }^{11}$ In other words, a rupture of chordae should happen if traction is applied on a normal chorda of $1 \mathrm{~mm}^{2}$ and of a prolapsed area if the tension is 35 times superior to the physiologic traction. This is highly unlikely to happen, meaning that the ruptures of the chordae we encountered among our patients are likely a consequence of the fragility of the dystrophic chordae. Moreover, we noticed that the forces applied to the subvalvular apparatus vary with respiration. This might account for why some exceptional thoracic traumatism with the sudden increase of the intrathoracic pressure can lead to traumatic rupture of normal chordae and acute MR. ${ }^{12,13}$

Gore-Tex sutures (CV-4 or CV-5; Gore-Tex Medical, W.L. Gore \& Assoc, Flagstaff, Ariz) are typically used as neochordae. The strength of these sutures is perfectly adapted as artificial chordae. ${ }^{14}$

The measures presented herein are only valid for primary human chordae of 0.7 to $0.8 \mathrm{~mm}$, and are attached to the free edge of the leaflets. This is probably different for secondary chordae (basal chordae or strut chordae), which are thicker $(1.2-1.3 \mathrm{~mm})$ and are not involved in neochordae implantations. Our team has already reported the various functions of primary and secondary chordae, and it is important to distinguish their specific roles. ${ }^{15}$

The tension applied to chordae holding 1 mitral segment is divided by the number of chordae set in tension. Tension decreased as the number of chordae set in tension increased. 


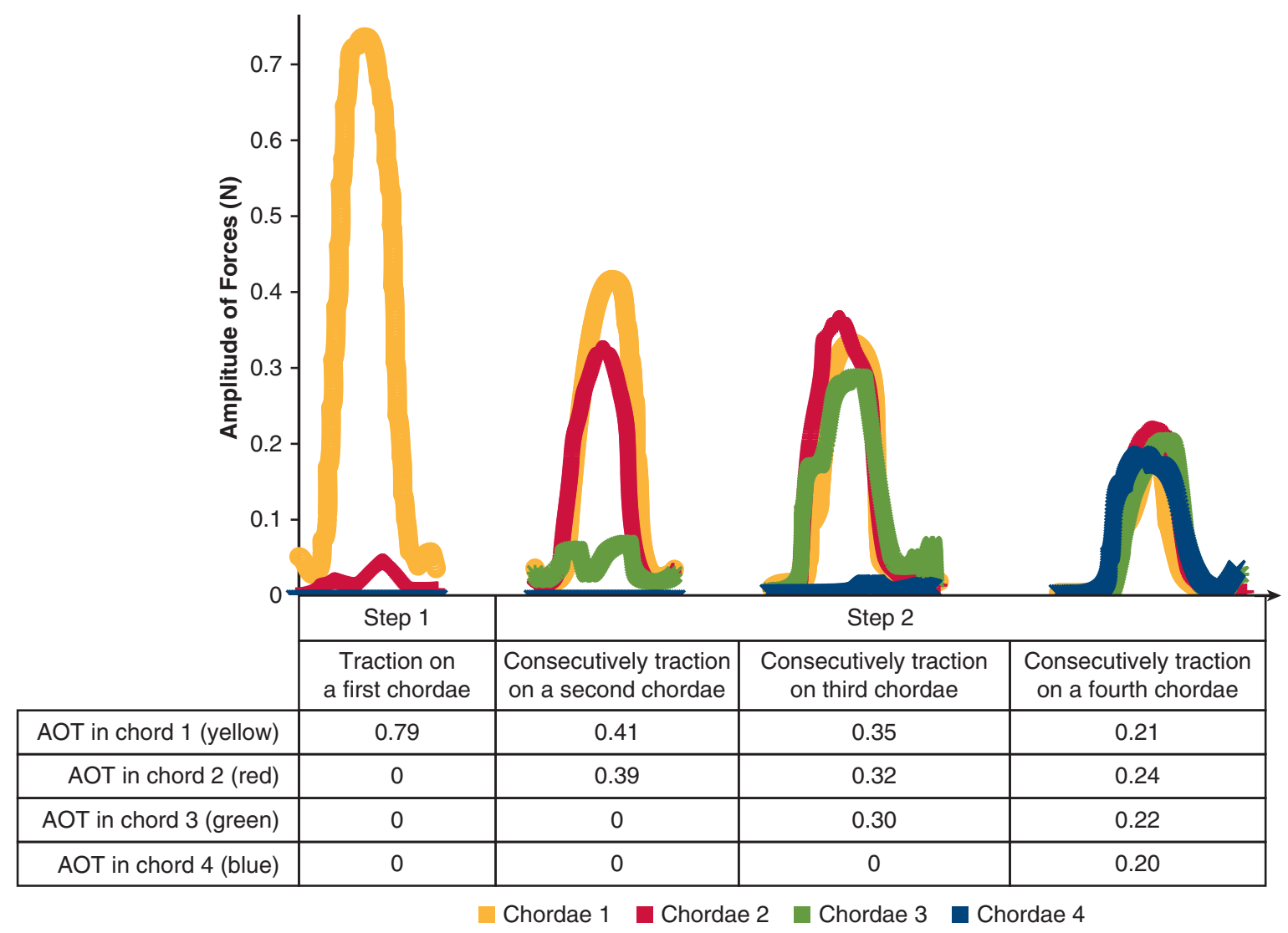

FIGURE 4. Schematic representation of the evolution of amplitude of tension (AOT, in newtons) in chordae during step 2: while pulling the first chorda (yellow), the amplitude of tension was $0.79 \mathrm{~N}$. The other chordae were then pulled consecutively. At the end of this phase the initial tension was divided by the total number of chordae set in tension.

This finding, although intuitively expected, is physically confirmed in our study, with an almost strict mathematical correlation.

The spider-web structure of the subvalvular apparatus, with numerous chordae and numerous implantation sites on the leaflets, is essential. We could extrapolate that it is also necessary to use several chordae to fix a prolapse segment all along its free edge, moreover if it is a large prolapse segment. An increased number of chordae would likely make the repair less fragile and more durable.

The tension of the subvalvular apparatus is low when the control of the regurgitation is optimal. This is the most important finding of this study. The normal valve seems to work in a low-stress regimen. In other words, in a physiological state, the perfect systolic closure of the mitral valve with 2 coapted leaflets inside a 3 -D saddle shape annular plan corresponds to the situation with the lowest tension on the subvalvular apparatus.

Few physiological explanations can be suggested to explain this finding (Figure 6):

- As mentioned previously, the total tension is divided by the number of chordae. After MR correction, the global tension is distributed between native and artificial chordae. Thus, the tension applied on neochordae (the only one that we can measure) is decreased.

- In the classical posterior prolapsed situation, the shape of the pathological leaflet formed a funnel, leading the blood flow toward the prolapsed area. Thus, the tension of the subvalvular apparatus of this zone is maximum.

- Because the 2 leaflets lean against each other, the vertical vector of tension applied on the free edges (toward the left atrium) decrease and thus the measured tension on the primary chordae decrease.

- The force of coaptation might increase. This hypothesis is supported by Falk and colleagues, who reported that greater coaptation distance might contribute to a more durable result after repair. ${ }^{16}$

- A part of the tension is transferred laterally, to the secondary chordae (not measured in our study), to the annulus and to the heart walls. Nielsen and colleagues also reported a significant reduction of the tension on the secondary chordae after mitral ring annuloplasty, without affecting the tension on the primary chordae. ${ }^{17}$

- The absence of regurgitation is associated with a normal intraventricular blood flow, with a normal clockwise 


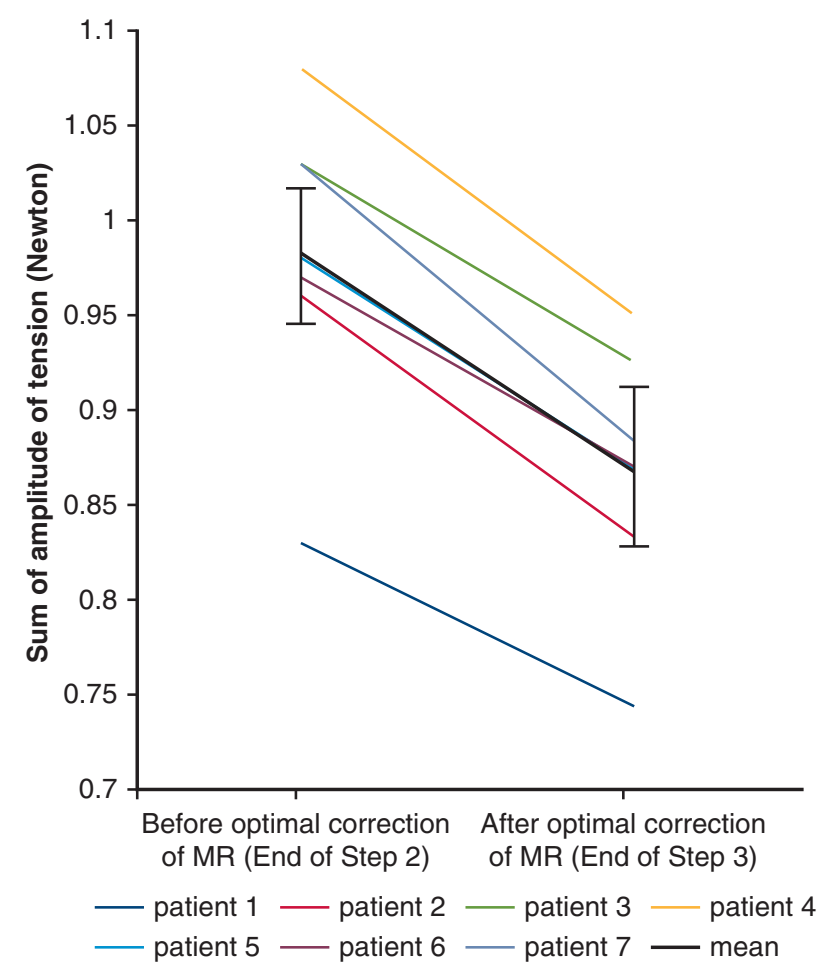

FIGURE 5. The sum of tension on all chordae before and after obtaining of an optimal echocardiographic correction (step 3). When all chordae were pulled to distribute tension equally to each chorda, a residual mitral regurgitation $(M R)$ or a billowing might persist, and an additional fine simultaneous traction on all chordae was required. After achieving a perfect echocardiographic result, the mean sum of amplitude of tension decreased from $0.98 \pm 0.08 \mathrm{~N}$ to $0.87 \pm 0.07 \mathrm{~N}$, corresponding to significant reduction of $12 \pm 2 \%(P=.018)$. In a "physiological-like" state, the subvalvular apparatus was in a low-stress state.

vortex. ${ }^{18}$ The ejection flow is then directed more toward the outflow tract and less to the mitral valve, lowering the chordae tension.

This observation gives a plausible proposition of the natural history of the primary MR. As the valve starts to leak, the tension on the chordae increases, leading to a vicious cycle and an accelerated progression of the regurgitation. Whereas restoring a large surface of coaptation increases this keystone effect, and decreases the stress on the chordae, ensures the long-term stability of the surgical repair, as usually reported in clinical settings. ${ }^{19,20}$

Although not directly supported by this study, it is likely that downsizing annuloplasty leads to a greater apposition of the 2 leading leaflets, with the keystone effect leading to a decreased tension on the chordae. While we are approaching the limits of existing tools to explore mitral valve function and the consequences of repair techniques, we are continuing to develop innovative tools (numerical simulation, medical imaging, new sensors) to assess these hypotheses.

\section{Clinical Effect of the Use of the Measuring Platform}

In conventional surgical $\mathrm{MVr}$, the only existing tool available to evaluate immediate success of a repair is the saline test (also potentially paired with an ink test). When neochordae are implanted the length adjustment on arrested hearts relies mainly on the habits of the surgeons. Dozens of tips and tricks have been proposed. ${ }^{21}$

A change of paradigm recently occurred with the introduction of novel techniques performed on beating hearts like transapical neochordae implantations allowing realtime adaptation of the repair thanks to intraoperative TEE control. It is also possible to fix the length of the chordae exactly to the optimal position; neither too long nor too short. This represents a potential advantage of transapical neochordae implantation over traditional surgical techniques.

This feature has been exploited in this work; additionally, to a strict morphological assessment, the plasty was optimized thanks to an objective parameter. A recent large cohort study that evaluated midterm results of NeoChord reported a $10 \%$ technical failure despite initial good echocardiographic results. ${ }^{22}$ We can assume that for $10 \%$ of cases TEE was not sensitive enough alone in guidance for NeoChord placement and adjustment. We found that in optimal repairs chordae tension was minimum and homogeneously spread on all chordae. We can thus hypothesize that measurement of chordae tension could be use in addition to TEE to ensure an optimal procedure. However, these beneficial characteristics remain to be validated by additional studies.

Finally, although our measuring device was initially developed to assess chordae tension, its use revealed interesting features for chordae length adjustment:

- Simplicity while avoiding iterative forceps manipulation on neochordae at the cardiac apex, without increasing the operative time (operative time of our center with the use of the platform are similar with those reported by reference centers ${ }^{23}$ ). The setup of the platform is simple.

- Precision, thanks to a millimetric per chorda or global adjustment.

- Safety, thanks to permanent control of applied tension during the procedure, avoiding excess traction on the frail valvular tissue.

Thus, even without tension assessment, the use of the device might also be beneficial for safety and precision.

\section{Study Limitation}

The neochordae (e-PTFE CV-4 Gore-Tex sutures) attached to the valve comes out through the ventricle wall. The resistance of this passageway is not quantifiable, but it is probably minimal. Relative to the resistance, the length and traction direction of the neochord (from the free edge to 

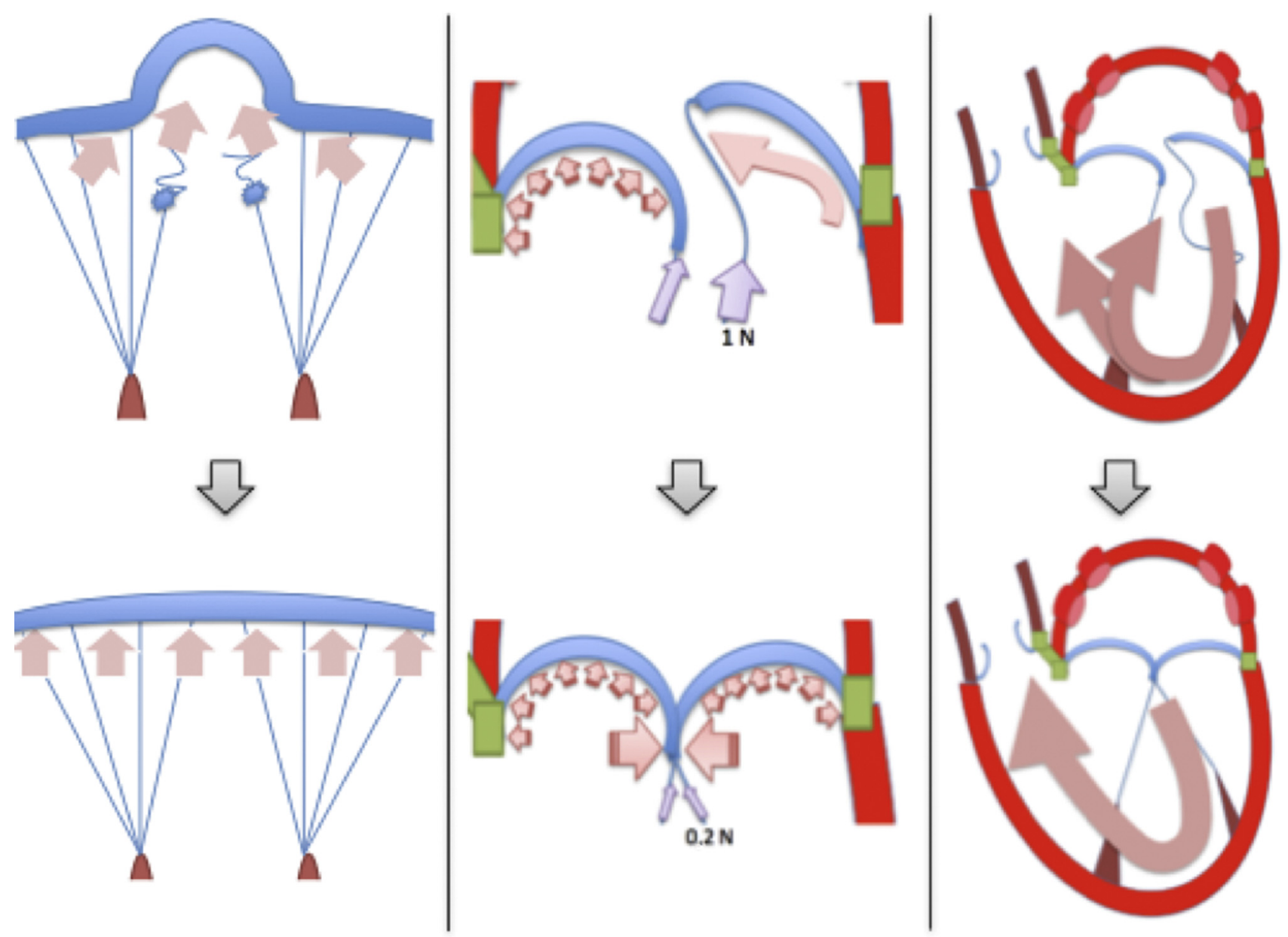

FIGURE 6. Hypotheses explaining the change in chordae tension under normal and pathological states. Three main hypotheses might participate in the reduction in total chordal tension occurring during the fine adjustment of chordae traction: the loss of "funnel effect" directing the flow toward the prolapse zone (left); the mutual abutment of the leaflets edge-to-edge with a "key-stone effect" (middle); and the return to normal clockwise intraventricular vortex with an ejection flow directed toward the outflow tract and not toward mitral leaflets (right).

the apex) are more important, which are different from those of the native chordae (from the free edge to the papillary muscle; Figure 7). Even if the NeoChord procedure recommends the introduction of the device as laterally as possible, we remain at some distance from the papillary muscles, and it is likely that the forces applied on the native chordae are slightly different. ${ }^{10,24}$ Nevertheless, the global understanding of the subvalvular function and its usefulness for assessment of the optimal length during this procedure remains valid.

\section{Perspectives}

Our findings have helped generate new hypotheses about mitral valve function, as well as raised many as yet unanswered questions. Concerning a clinical perspective, the prognostic value of measured tension and its ability to improve long-term success repair rate will be obtained thanks to the prospective follow-up of this cohort. In our center, the platform is used for all implantations. We are currently pursuing the optimization of the platform before its duplication to allow its assessment by other expert teams.

Concerning experimental perspectives, we reached some limits of our clinical model. Ex vivo studies are currently performed to compare the different technologies for chordae tension measurement as well as measuring the effect of the differences in axis and length of neochordae implanted transapically compared with the conventional implantation. Larger projects involving multiple technologies (medical imaging, numerical simulation) are required to better understand the changes in structure and flow occurring during transapical neochordae implantations.

From a more global perspective, in conventional surgical repairs many different repair techniques are continuously described, and multiple prosthetic devices are available (eg, band, rigid annuloplasty ring, etc). Nonetheless, morphologic assessment tools failed to determine the best surgical options and the surgeon's expertise primes above objective concrete data. 


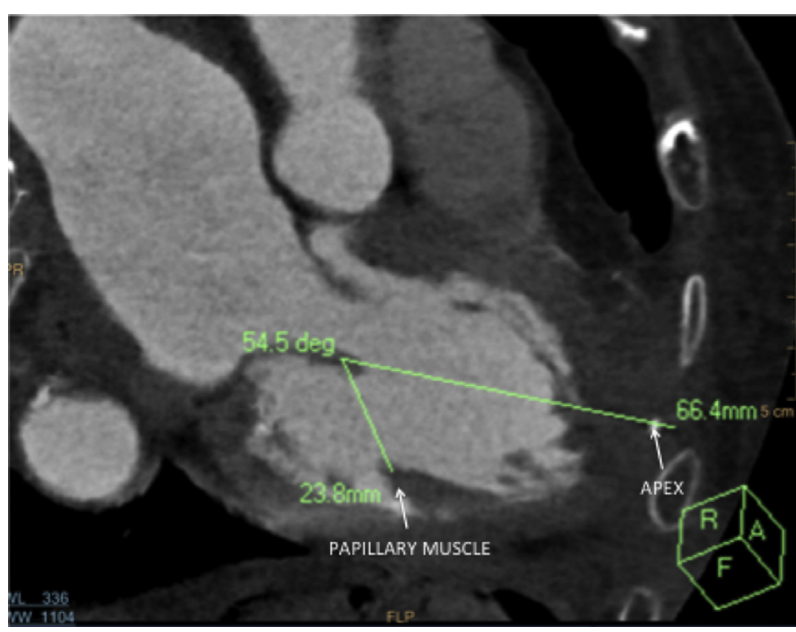

FIGURE 7. Difference in axis between native chordae and transapical neochordae. In this case the apical neochordae insertion site was marked with a metal clip during the procedure. A postoperative computed tomography scan was performed allowing the visualization of the free edge of the posterior leaflet, the summit of the posterior papillary muscle, and the apex. The angle of the native chordae (between the papillary muscle and the free edge of the leaflet) and the neochordae (between the clip and the free edge of the leaflet) was $54^{\circ}$. The length of the native chordae was also shorter than that of the neochordae.

New beating heart valve treatments have already grown in popularity as devices and quality of the 3-D images improved. Percutaneous repair techniques have a single anatomical target, in opposition to the conventional surgery that often deals with multiple repair actions. Combination procedures appear promising. However, as for conventional surgery, the role of annuloplasty to other techniques remains to be determined as well as the criteria for their implantation. Original measuring tools allowing real-time intraoperative measurement (in addition to standard morphologic evaluation) could increase our capacity to treat patients with customized techniques guided by objective data during surgical and percutaneous interventions.

\section{CONCLUSIONS}

Transapical neochordae implantation conducted on a beating and functional heart, provides an excellent model for in vivo study of the tension forces on neochordae. This work brings original and useful data concerning the physiopathology of the subvalvular apparatus: the tension applied on human chordae to sustain the P2 segment of the mitral posterior leaflet is low $(1 \mathrm{~N})$; this tension is divided by the number of chordae holding this segment; during $\mathrm{MVr}$ the lowest tension on all neochordae is observed when the control of the regurgitation is optimal. Such advances help to better understand $\mathrm{MVr}$ and, consequently, might play a role in the future treatment of mitral valve disease. Along with this objective assessment, the tool developed allows a safe, precise, and reproducible procedure.

\section{Conflict of Interest Statement}

Jean-François Obadia discloses research support from Boehringer, Abbott, Medtronic, and Edwards; consulting fees/honoraria from Edwards, Abbott, Medtronic, Servier, and Novartis; and royalty income from Landanger, and Delacroix-Chevalier. All other authors have nothing to disclose with regard to commercial support.

The authors thank Dr Anelechi Anyanwu, Young Joon Kwon, MSE for their help in preparing the manuscript, and are thankful for the support from the Fulbright program, the "Fédération Française de Cardiologie" Doctoral Fellowship program, the Centre d'Investigation Clinique of Hospice Civils de Lyon, and the Philippe Foundation.

\section{References}

1. Carpentier A. Cardiac valve surgery-the "French correction" J Thorac Cardiovasc Surg. 1983;86:323-7.

2. Tourmousoglou C, Lalos S, Dougenis D. Mitral valve repair of isolated posterior leaflet prolapse: resect or respect? Interact Cardiovasc Thorac Surg. 2014;19: 1027-35.

3. Colli A, Zucchetta F, Torregrossa G, Manzan E, Bizzotto E, Besola L, et al. Transapical off-pump mitral valve repair with Neochord implantation (TOPMINI ): step-by-step guide. Ann Cardiothorac Surg. 2015;4:295-7.

4. Siefert AW, Rabbah JP, Pierce EL, Kunzelman KS, Yoganathan AP. Quantitative evaluation of annuloplasty on mitral valve chordae tendineae forces to supplement surgical planning model development. Cardiovasc Eng Technol. 2014;5:35-43.

5. Jimenez JH, Soerensen DD, He Z, Ritchie J, Yoganathan AP. Mitral valve function and chordal force distribution using a flexible annulus model: an in vitro study. Ann Biomed Eng. 2005;33:557-66.

6. Jimenez JH, Soerensen DD, He Z, Ritchie J, Yoganathan AP. Effects of papillary muscle position on chordal force distribution: an in-vitro study. $J$ Heart Valve Dis. 2005; 14:295-302.

7. Nielsen SL, Soerensen DD, Libergren P, Yoganathan AP, Nygaard H. Miniature C-shaped transducers for chordae tendineae force measurements. Ann Biomed Eng. 2004;32:1050-7.

8. Nielsen SL, Nygaard H, Fontaine AA, Hasenkam JM, He S, Andersen NT, et al. Chordal force distribution determines systolic mitral leaflet configuration and severity of functional mitral regurgitation. J Am Coll Cardiol. 1999; 33:843-53.

9. He Z, Jowers C. A novel method to measure mitral valve chordal tension. J Biomech Eng. 2009;131:014501.

10. Jensen H, Jensen MO, Waziri F, Honge JL, Sloth E, Fenger-Gron M, et al. Transapical neochord implantation: is tension of artificial chordae tendineae dependent on the insertion site? J Thorac Cardiovasc Surg. 2014; 148:138-43.

11. Zuo K, Pham T, Li K, Martin C, He Z, Sun W. Characterization of biomechanical properties of aged human and ovine mitral valve chordae tendineae. $J \mathrm{Mech} B e-$ hav Biomed Mater. 2016;62:607-18.

12. Luecke T, Pelosi P. Clinical review: positive end-expiratory pressure and cardiac output. Crit Care. 2005;9:607-21.

13. Santamore WP, Bove AA, Heckman JL. Right and left ventricular pressurevolume response to positive end-expiratory pressure. Am J Physiol. 1984;246: H114-9.

14. Dang MC, Thacker JG, Hwang JC, Rodeheaver GT, Melton SM, Edlich RF. Some biomechanical considerations of polytetrafluoroethylene sutures. Arch Surg. 1990;125:647-50.

15. Obadia JF, Casali C, Chassignolle JF, Janier M. Mitral subvalvular apparatus: different functions of primary and secondary chordae. Circulation. 1997;96: 3124-8.

16. Falk V, Seeburger J, Czesla M, Borger MA, Willige J, Kuntze T, et al. How does the use of polytetrafluoroethylene neochordae for posterior mitral valve prolapse 
(loop technique) compare with leaflet resection? A prospective randomized trial. J Thorac Cardiovasc Surg. 2008;136:1205; discussion:1205-6.

17. Nielsen SL, Lomholt M, Johansen P, Hansen SB, Andersen NT, Hasenkam JM. Mitral ring annuloplasty relieves tension of the secondary but not primary chordae tendineae in the anterior mitral leaflet. J Thorac Cardiovasc Surg. 2011;141: 732-7.

18. Nakashima K, Itatani K, Kitamura T, Oka N, Horai T, Miyazaki S, et al. Energy dynamics of the intraventricular vortex after mitral valve surgery. Heart Vessels. 2017;32:1123-9.

19. David TE, Armstrong S, McCrindle BW, Manlhiot C. Late outcomes of mitral valve repair for mitral regurgitation due to degenerative disease. Circulation. 2013; 127:1485-92.

20. Lazam S, Vanoverschelde JL, Tribouilloy C, Grigioni F, Suri RM, Avierinos JF, et al. Twenty-year outcome after mitral repair versus replacement for severe degenerative mitral regurgitation: analysis of a large, prospective, multicenter, international registry. Circulation. 2017;135:410-22.
21. Ibrahim M, Rao C, Athanasiou T. Artificial chordae for degenerative mitral valve disease: critical analysis of current techniques. Interact Cardiovasc Thorac Surg. 2012;15:1019-32.

22. Colli A, Manzan E, Aidietis A, Rucinskas K, Bizzotto E, Besola L, et al. An early European experience with transapical off-pump mitral valve repair with NeoChord implantation. Eur J Cardiothorac Surg. 2018;54:460-6.

23. Colli A, Bagozzi L, Banchelli F, Besola L, Bizzotto E, Pradegan N, et al Learning curve analysis of transapical NeoChord mitral valve repair. Eur J Cardiothorac Surg. 2018;54:273-80.

24. Caimmi PP, Sabbatini M, Fusaro L, Borrone A, Cannas M. A study of the mechanical properties of ePTFE suture used as artificial mitral chordae. J Card Surg. 2016;31:498-502.

Key Words: mitral valve repair, NeoChord, transapical, chordal tension, mitral physiology

Readers who found these articles interesting may also like to read the following papers found in recent and future issues of our sister publications, Seminars in Thoracic and Cardiovascular Surgery and Operative Techniques in Thoracic and Cardiovascular Surgery!

\section{Adult: Mitral Valve}

ORIGINAL SUBMISSION: The Clinical Significance of Cerebral Microbleeds in Infective Endocarditis Patients. Ryosuke Murai. Semin Thoracic Surg 2019: 51-58.

Commentary: The truth perturbs in the seemingly negligible; brain magnetic resonance imaging and endocarditis. Ari A. Mennander. Semin Thoracic Surg 2019: 59-60.

ORIGINAL MANUSCRIPT: Mathematical Blueprint of a Mitral Valve. Pramod N. Bonde. Semin Thoracic Surg 2019: In press.

Commentary: Simulating the mitral apparatus. Antonio Miceli. Semin Thoracic Surg 2019: In press.

SURGICAL TECHNIQUE: Five Maneuvers to Facilitate Faster Robotic Mitral Valve Repair. Marc Gillinov. Semin Thoracic Surg 2019: 48-50.

CASE REPORT: Minimally Invasive SAPIEN in Mitral Annular Calcification Following Transcatheter Aortic Valve Replacement: Feasibility and Lessons Learned. Tom C. Nguyen. Semin Thoracic Surg 2018: 290-292. 